\title{
Learning Style Preferences Among Undergraduate Medical Students: An Experience from Different Medical Colleges of Bangladesh
}

\author{
Dr. Md. Rezaul Karim ${ }^{l}$, Prof. Dr. AKM Asaduzzaman ${ }^{2}$, Prof. Dr. Md. Humayun Kabir Talukder ${ }^{3}$, Dr Kazi Khairul Alam ${ }^{4}$, \\ Dr. Farhana Haque, Dr. Sadia Jabeen Khan ${ }^{6}$
}

\begin{abstract}
This descriptive type of cross sectional study was conducted to determine the learning styles of undergraduate medical students. The study period was from July 2017 to June 2018 . The study was carried out among the students of $2^{\text {nd }}, 3^{\text {rd }}$ and $4^{\text {th }}$ phases of MBBS course of 3 government and 4 non-government medical colleges of Bangladesh. Out of 7 medical colleges, 4 were within Dhaka and 3 were from outside Dhaka. The sample size was 1004 students. Medical colleges were selected purposively and convenience sampling technique was adopted for data collection. Bangla translated version Fleming's VARK (visual, auditory, read/write and kinesthetic) questionnaire was used to identify the learning styles of students.

The study revealed that out of 1004 medical students, $64.2 \%$ preferred multimodal learning styles and rest $35.8 \%$ preferred unimodal learning styles. Among unimodal learning preferences, auditory (A) and kinesthetic (K) were the most preferred sensory modalities of learning. Among multimodal learning styles preferences, the combination of auditory \& kinesthetic (AK) and auditory, read/write \& kinesthetic (ARK) were predominant. There were only significant differences of the mean scores of visual (V) learning style among the male and female students.

Majority of students preferred multimodal learning styles. Students are able to learn effectively as long as the teacher provides a blend of visual, auditory, read/writing and kinesthetic activates. The study recommended that teachers should be aware of the medical students' learning styles and aligning teaching-learning methods with learning styles will improve their learning and academic performance.
\end{abstract}

Keywords: Learning styles, Undergraduate medical students

\section{Introduction}

'Learning style' is the individual's preferred method of gathering, processing, interpreting, organizing and analyzing the information ${ }^{1}$. Herbert Thelen first introduced the term "learning style" in $1954^{2}$. The idea of individualized learning styles became popular in the 1970s. Genetic traits, past experiences, and social environment help determining predominant learning styles of individuals ${ }^{3}$.

There are many different models available for assessing learning styles. Some of these models include Honey and Mumford, VARK by Fleming and Kolb's learning model.

\footnotetext{
1 Junior consultant (Medicine), DGHS, Mohakhali, Dhaka

2. Professor, Community Medicine, Diabetic Association Medical College, Faridpur

3. Professor, Curriculum Development \& Evaluation Centre for Medical Education (CME), Mohakhali, Dhaka.

4. Assistant Professor, Medical Education Centre for Medical Education (CME), Mohakhali, Dhaka.

5. Junior consultant (Gynae), DGHS, Mohakhali, Dhaka

6. Junior consultant (Gynae), DGHS, Mohakhali, Dhaka

Address of correspondence:

Dr. Md. Rezaul Karim

Junior consultant (Medicine), DGHS, Mohakhali, Dhaka Email: dr.rezaul33@gmail.com
}

These learning styles models are based on different learning theories, principles of learning and psychological constructs $^{4}$. The VARK model developed by Fleming and Mills is concise, appropriate, simple and reliable and therefore considered in this study ${ }^{5}$.

VARK is an acronym for the Visual (V), Auditory (A), Read/Write (R) and the Kinesthetic (K) sensory modalities. It provides learners the insight into their preferred sensory modalities in perceiving the information. For the best information processing the visual learners learn better when the study material is presented as graphs, pictures, diagrams, an handouts, the auditory learners on hearing information through lectures, discussions, and tapes, the read-write learners by text-book reading and notes writing and kinesthetic learners learn by doing experiments, dissections, case history taking and clinical examination ${ }^{6}$. Students may learn by single mode (unimodal), two modes (bimodal), three modes (trimodal) or all four modes (quadrimodal) of the information presentation? ${ }^{7}$. The same student can exhibit different approaches to studying depending upon the content, context, and demands of particular tasks ${ }^{8}$.In medical education, different learners have different learning styles. The instructional methods used to teach undergraduate medical student include lectures, practical sessions, tutorials, demonstrations, seminar and bedside teaching in order to impart and acquire knowledge. If the instructional methods conform to their learning style they learn better and

Bangladesh Journal of Medical Education 2019;10(2):26-30. (C) 2019 Karim S et al., publisher and licensee Association for Medical Education. This is an Open Access article which permits unrestricted non-commercial use, provided the original work is properly cited. 
this may enhance the performance of students. While disparity can result in failure, that's why there is a great deal of interest amongst educators in identifying preferable learning styles of their students and "tailor instructions" in such a way that the medical students appreciate and follow it to learning'.

\section{Methods}

This was a descriptive type of cross sectional study. The study period was from July 2017 to June 2018 . The study was carried out among the students of $2^{\text {nd }}, 3^{\text {rd }}$ and $4^{\text {th }}$ phases of MBBS course of 3 government and 4 non-government medical colleges of Bangladesh. Out of 7 medical colleges, 4 were within Dhaka and 3 were from outside Dhaka. The sample size was 1004 students. Medical colleges were selected purposively and convenience sampling technique was adopted for data collection. Foreign students were excluded from the study.

A self-administered structured questionnaire including VARK (visual, auditory, read/write and kinesthetic) version 7.3 was used. Fleming and Miles' VARK assessment questionnaire were used because it is a recognized, well tested, and validated tool to assess students' learning styles ${ }^{10}$. It consists of 16 questions with 4 options each. Students could choose more than one option of each question for identifying their learning styles. The purpose of each question is also to identify their preferred learning styles. For easy understanding, these 16 questions were customized and translated into Bangla considering the country context. The study protocol and instruments were approved by the institutional review board (IRB) of the Center for Medical Education(CME), Mohakhali Dhaka.

The specific time was taken from the class teacher to collect data from the students. The students were free to either participate or not participate in the study. After briefly explaining the purpose and procedure of the study, the questionnaires were distributed to the students to give their opinions/views. Completed questionnaires were collected.

Data were analyzed by SPSS, version 20. Descriptive statistics were used to identify the learning styles of students. Chi-square test was used to compare four VARK learning styles between male and female students. ANOVA was used to compare four VARK learning styles among students of different phases.

\section{Results}

A total of 1004 undergraduate medical students have participated in this study. Of them, $50.3 \%$ were studying in the medical colleges that located in Dhaka and rest $49.7 \%$ located out of Dhaka. On the other hand, $50.5 \%$ were studying in the government medical colleges and rest $49.5 \%$ in non-government medical colleges.
Among the medical students who participated in this study, $64.2 \%$ preferred multimodal learning styles and rest $35.8 \%$ preferred unimodal learning styles. In both sex, multimodal learning styles preference were predominant (Table 1). Among the multimodal preferences, $32.5 \%$ bimodal, $21.4 \%$ trimodal and only $10.4 \%$ were quadrimodal of VARK learning styles (Figure 1).

Table 1: Distribution of learning styles preferences and gender among the undergraduate medical students.

\begin{tabular}{lccc}
\hline & \multicolumn{2}{c}{ Gender } & \\
\cline { 2 - 3 } Learning styles & Male n (\%) & Female n (\%) & Totaln (\%) \\
\hline Unimodal & $130(12.9 \%)$ & $229(22.8 \%)$ & $359(35.8 \%)$ \\
Multimodal & $249(24.8 \%)$ & $396(39.4 \%)$ & $645(64.2 \%)$ \\
Total & $\mathbf{3 7 9 ( 3 7 . 7 \% )}$ & $\mathbf{6 2 5}(\mathbf{6 2 . 3 \% )}$ & $\mathbf{1 0 0 4}(\mathbf{1 0 0 \% )}$ \\
\hline
\end{tabular}

Among the unimodal learning style preferences, Auditory $(19.5 \%)$ and Kinesthetic $(11.3 \%)$ were predominant. Among the bimodal learning styles, the combination of Auditory and Kinesthetic (AK) 15.9\% and among the tri-modal learning styles, the combination of Auditory, Read/write \& Kinesthetic (ARK) 12.9\% preferences were predominant. Only $10.4 \%$ were used to all four modes of VARK (Figure 2 ). It was interesting to note that only $7.65 \%$ of medical students had awareness about their own learning styles and rest $92.35 \%$ did not have awareness about their own learning styles (Figure 3).

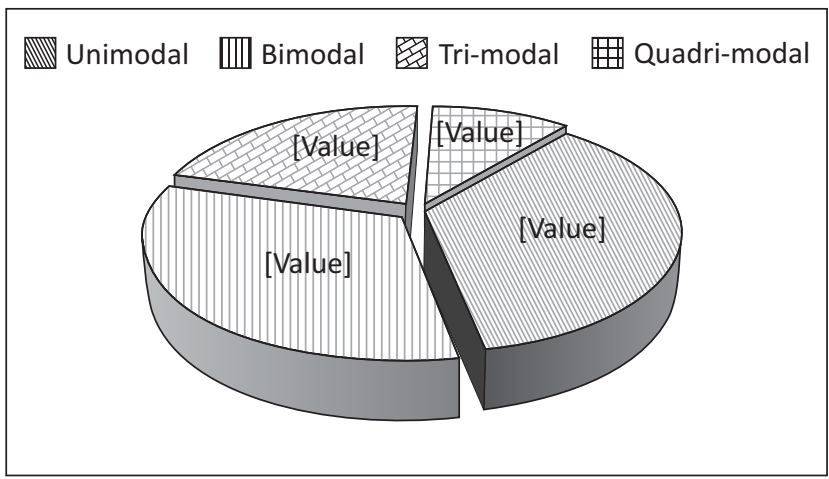

Figure 1: Distribution of students by their (major) learning styles $(n=1004)$ 


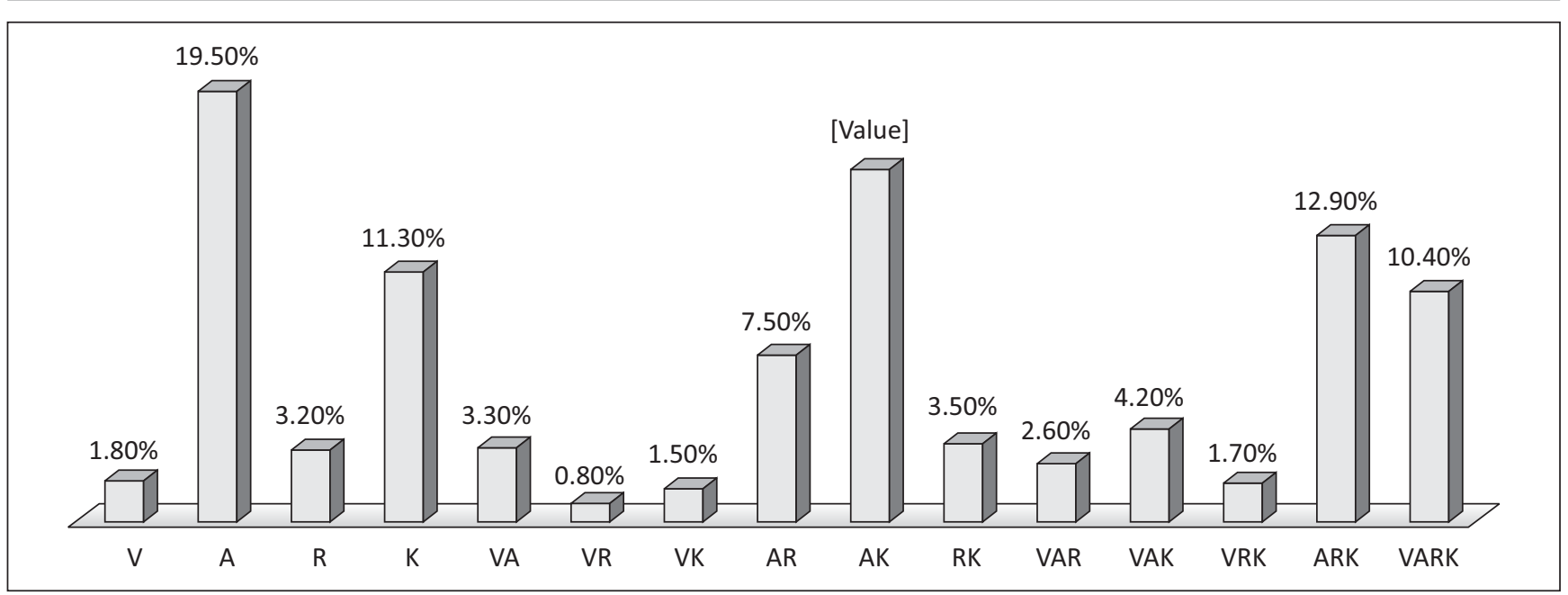

Figure 2: Distribution of learning style preferences of medical students

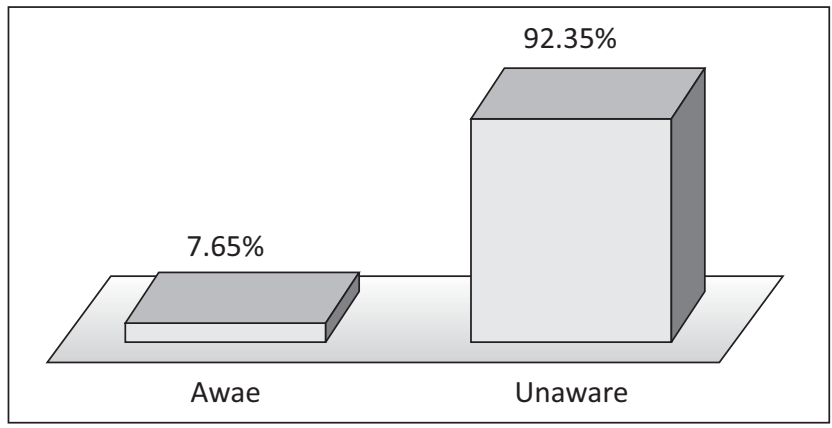

Figure 3: Distribution of medical students by their awareness of own learning styles $(\mathrm{n}=915)$

There were only significant differences of the mean scores of visual learning styles among the male and female students, but the effect size was only 0.1906 . There were no significant differences of the scores of other three learning styles (Auditory, Read/write and Kinesthetic) among the students in relation to their gender (Table 2). There were only significant differences of the mean scores of visual, auditory and kinesthetic learning styles of VARK mood among the student of different phases, but the effect size ranged from 0.1679 to 0.2109 (Table 3 ).
Table 2: Comparison of four VARK learning styles between male and female student

\begin{tabular}{lcccc}
\hline VARK mode & Gender & Mean \pm SD & $\begin{array}{c}\text { t (df) } \\
\text { Cohens' d }\end{array}$ & P \\
\hline \multirow{4}{*}{ Visual } & $\begin{array}{c}\text { Male } \\
(\mathrm{n}=379)\end{array}$ & $4.58 \pm 2.8573$ & $\begin{array}{c}2.953 \\
(1002)\end{array}$ & $0.003^{*}$ \\
& $\begin{array}{c}\text { Female } \\
(\mathrm{n}=625)\end{array}$ & $4.05 \pm 2.7508$ & 0.1906 & \\
Auditory & $\begin{array}{c}\text { Male } \\
(\mathrm{n}=379)\end{array}$ & $7.41 \pm 2.6753$ & $\begin{array}{c}-0.546 \\
(1002)\end{array}$ & 0.585 \\
& $\begin{array}{c}\text { Female } \\
(\mathrm{n}=625)\end{array}$ & $7.50 \pm 2.6464$ & 0 & \\
Read/write & $\begin{array}{c}\text { Male } \\
(\mathrm{n}=379)\end{array}$ & $5.61 \pm 2.3807$ & 0.046 & \\
& $\begin{array}{c}\text { Female } \\
(\mathrm{n}=625)\end{array}$ & $5.60 \pm 2.2195$ & 0 & \\
& $\begin{array}{c}\text { Male } \\
(\mathrm{n}=397)\end{array}$ & $5.53 \pm 2.8371$ & -0.345 & \\
\hline Kinesthetic & $\begin{array}{c}\text { Female } \\
(\mathrm{n}=625)\end{array}$ & $6.59 \pm 2.6383$ & 0.963 & \\
\hline
\end{tabular}

"Equality of Variances not assumed by Levene's test; hence, Welch t test was applied. 
Table 3: Comparison of four VARK learning styles among students of different phases

\begin{tabular}{|c|c|c|c|c|}
\hline \multirow[b]{2}{*}{ VARK mode } & \multirow[b]{2}{*}{$\begin{array}{c}\text { Phase of } \\
\text { study }\end{array}$} & \multirow[b]{2}{*}{ Mean \pm SD } & \multicolumn{2}{|c|}{ Statistics } \\
\hline & & & $\begin{array}{c}F\left(d_{f_{B}}, d f_{w}\right) \eta^{2} \\
\left(\text { Cohens' }^{\prime}\right)\end{array}$ & $\mathbf{P}$ \\
\hline \multirow{3}{*}{ Visual } & $\begin{array}{l}2^{\text {nd }} \text { Phase } \\
(n=345)\end{array}$ & $4.64 \pm 2.9021$ & \multirow{3}{*}{$\begin{array}{c}5.406 \\
(2,1001) \\
0.011 \\
(0.2109)\end{array}$} & \multirow{3}{*}{$0.005 *$} \\
\hline & $\begin{array}{l}3^{\text {rd }} \text { Phase } \\
(n=387)\end{array}$ & $3.99 \pm 2.7892$ & & \\
\hline & $\begin{array}{l}4^{\text {th }} \text { Phase } \\
(n=272)\end{array}$ & $4.11 \pm 2.6419$ & & \\
\hline \multirow{3}{*}{ Auditory } & $\begin{array}{l}2^{\text {nd }} \text { Phase } \\
(\mathrm{n}=345)\end{array}$ & $7.68 \pm 2.6406$ & \multirow{3}{*}{$\begin{array}{c}3.527 \\
(2,1001) \\
0.007 \\
(0.1679)\end{array}$} & \multirow{3}{*}{$0.030 *$} \\
\hline & $\begin{array}{l}3^{\text {rd }} \text { Phase } \\
(n=387)\end{array}$ & $7.51 \pm 2.6471$ & & \\
\hline & $\begin{array}{l}4^{\text {th }} \text { Phase } \\
(\mathrm{n}=272)\end{array}$ & $7.12 \pm 2.6652$ & & \\
\hline \multirow{3}{*}{ Read/write } & $\begin{array}{l}2^{\text {nd }} \text { Phase } \\
(n=345)\end{array}$ & $5.77 \pm 2.2779$ & \multirow{3}{*}{$\begin{array}{c}1.699 \\
(2,1001) \\
0.003 \\
(0.1097)\end{array}$} & \multirow{3}{*}{0.183} \\
\hline & $\begin{array}{l}3^{\text {rd }} \text { Phase } \\
(n=387)\end{array}$ & $5.57 \pm 2.2528$ & & \\
\hline & $\begin{array}{l}4^{\text {th }} \text { Phase } \\
(n=272)\end{array}$ & $5.44 \pm 2.3171$ & & \\
\hline \multirow{3}{*}{ Kinesthetic } & $\begin{array}{l}2^{\text {nd }} \text { Phase } \\
(n=345)\end{array}$ & $6.83 \pm 2.6517$ & \multirow{3}{*}{$\begin{array}{c}4.416 \\
(2,1001) \\
0.009 \\
(0.1906)\end{array}$} & \multirow{3}{*}{$0.012 *$} \\
\hline & $\begin{array}{l}3^{\text {rd }} \text { Phase } \\
(\mathrm{n}=387)\end{array}$ & $6.25 \pm 2.8116$ & & \\
\hline & $\begin{array}{l}4^{\text {th }} \text { Phase } \\
(n=272)\end{array}$ & $6.67 \pm 2.7138$ & & \\
\hline
\end{tabular}

\section{Discussion}

Health Profession usually requires several simultaneous skills involving sensory components such as visual (i.e., deciphering graphic content in research articles), auditory (i.e., listening to patients or clients), reading-writing (i.e., reading journal articles and keeping records) and kinesthetic (i.e., learning or performing physical exams and procedures). Thus in addition to improving their academic performance, knowledge of learning theory may help students become aware of and develop ways to master these lifelong professional skills. As an educator, it is important to know the preferred learning styles of the students. It helps the educators identify and solve learning problems among students, thus making them more effective learner. Knowing students' preferred learning style also helps to overcome the predisposition of many educators to treat all students in a similar way.

This study used the VARK questionnaire to determine the learning preferences of undergraduate medical students because it is a recognized, well tested, and validated tool to assess students' learning styles ${ }^{10}$. The VARK learning style questionnaire measure four sensory modalities used for learning, namely visual (V), auditory (A), read/write (R) and kinesthetic $(\mathrm{K})$. According to the individual preferences, the learner can be classified as unimodal if they show predominantly one learning preference or multimodal if they preference two (Bimodal), three (Trimodal) or four (Quadrimodal) learning style.

In the present study, a majority of the students (64.2\%) exhibited multimodal learning style (Table 1). Other studies that have used VARK learning style questionnaire also reported similar result (Kharb et al. 61\%, Bakan and Nacar $63.9 \%$, Khalid et al. $64.0 \%)^{7,11,3}$. A student who prefers multimodal learning style does not learn by simply sitting in a classroom listening to the educator, memorizing assignments. Thus, teaching should be a multisensory and filled with variety. Students are able to learn effectively as long as the teacher provides a blend of visual, auditory, $\mathrm{read} /$ writing and kinesthetic activates. The use of multimedia can represent multiple contents (text, animations and images) to accommodate for the students with diverse learning styles. According to the "meshing hypothesis" ${ }^{12}$ learning increases exponentially by incorporating the predominant learning styles in teaching ${ }^{13}$.

Among the unimodal learning style preferences auditory (A) $19.5 \%$ and kinesthetic (K) $11.3 \%$ learning styles were predominant. Among the bimodal learning styles the combination of Auditory and Kinesthetic (AK) 15.5\% and among the tri-modal learning styles the combination of Auditory, Read/write \& Kinesthetic (ARK) 12.9\% preferences were predominant (Figure 2). These results are similar to the study conducted by and Gayathri et al. Kharb et al. on the first year undergraduate medical student ${ }^{14,7}$.

In the present study, auditory and kinesthetic modes were most predominant among unimodal, and multimodal learning styles. So, if the information was given to students in connection with reality, experience and practice the students would acquire the information in a better way and learning can be accomplished effectively.

The students should have awareness about their own learning styles preferences, it will be helpful in the use of appropriate learning strategies that enable them to become lifelong and self-directed learners, thus maximizing their potential. In our study, it was interesting to note that only $7.65 \%$ medical students had awareness about their own learning styles and rest $92.35 \%$ did not have awareness about their own learning styles (Figure 3 ).

Two studies conducted by Gayathri et al. and Urval et al. showed that there were no differences in the learning styles preferences between the male and females ${ }^{14,15}$. Another study conducted by Kharb et al. showed that a significantly higher number of female students preferred the auditory mode of the learning style as compared to the males; whereas a significantly higher number of male students preferred the kinesthetic mode ( $p$ value $<0.05)^{7}$. In the present study, there were only significant differences of the mean scores of visual learning styles among the male and female students, but the effect size was only 0.1906 . There were no 
significant differences of the scores of other three learning styles (Auditory, Read/write and Kinesthetic) among the students in relation to their gender (Table 2). Considering the differing result from various studies, no generalizations can be made regarding the influence of sex. This study also found that there were significant differences mean scores of visual, auditory and kinesthetic learning styles of VARK mood among the students of different phases, but the effect size ranged from 0.167 to 0.210 (Table 3 ).

\section{Conclusion}

Every student has unique learning styles which may differ from others. Having the understanding of learning styles of students is very much important for both the medical teachers and the students. If the learners identify their learning preferences, it will be helpful in the use of appropriate learning strategies that enable them to become lifelong and self-directed learners, thus maximizing their potential. Teachers can incorporate learning styles in teaching-learning methods to maximize learning. This would not only create an efficient learning environment, but it would also motivate the students to achieve academic success.

\section{References}

1. Vinaya M, Podder S, Pradhan G. Learning styles and teaching-learning method preferences of second year medical undergraduates in pharmacology in a rural medical college. International Journal of Pharmacology Research. 2015; 5 (4): 203-206.

2. Ghaffari R, Ranjbarzadeh FS. The Analysis of Learning Styles and Their Relationship to Academic Achievement in Medical Students of Basic Sciences Program. Res Dev MedEduc. 2013; 2(2):73-76.

3. Khalid A, Rahim K, Bashir Z, Hanif A. Learning style preferences among students of shalamar medical and dental college, Pakistan. Adv Health Prof Educ. 2015; 1(1):13-17.

4. Coffield F, Moseley D, Hall E, Ecclestone K. Learning Styles and Pedagogy in Post-16 Learning: a systematic and Critical Review, London. 2004; Learning Skills and Research Center.
5. Shah C, Joshi N, Mehta HB, Gokhale PA. Learning styles adopted by medical students. International Research Journal of Pharmacy. 2011; 2(12), $227-9$.

6. Mukherjee S, Das S, De S, Mukhopadhyay D. Learning style preferences of first year medical students of a rural medical college, West Bengal, India. IJSR.2013; 2 (11), 10-13.

7. Kharb P, Samantha PP, Jindal M, Singh V. The learning and the preferred teaching-learning strategies of first year medical students. Journal of Clinical and Diagnostic Research.2013; 7(6): 1089-92.

8. Richardson JTE. Students' approaches to learning and teachers' approaches to teaching in higher education. Educational Psychology. 2005; 25(6), 673-80.

9. Chaudhary MH, Ayub S. Association of academic performance with learning style preference of medical students: Multi-center study from Pakistan. Journal of Contemporary Medical Education. 2015; 3 (2).

10. Leite WL, Svinicki M, Shi Y. Attempted validation of the scores of the VARK: learning styles inventory with multi trait multimethod confirmatory factor analysis models. Educ Psychol Meas. 2010; 70: 323-339.

11. Baykan Z, Nacar M. Learning styles of first-year medical students attending Erciyes University in Kayseri, Turkey. Adv Physiol Educ. 2007; 31: 158-160.

12. Pashler H, McDaniel M, Rohrer D, Bjork R. Learning Styles Concepts and Evidence. Psychol Sci Public Interest. 2008; 9(3):105-19.

13. Sankey MD, Birch D, Gardiner MW. The impact of multiple representations of content using multimedia on learning outcomes across learning styles and modal references. Intern JEduc Dev ICT. 2011; 7(3):18-35.

14. Gayathri B, Indhu K. A study of learning style preferences among first year undergraduate medical students using VARK model. Education in Medicine Journal. 2016; 8(4):15-21.

15. Urval RP, Kamath A, Ullal S, Shenoy AK, Shenoy N, Udupa LA. Assessment of learning styles of undergraduate medical students using the VARK questionnaire and the influence of sex and academic performance. Adv Physiol Educ. 2014; 38: 216-22.

Bangladesh Journal of Medical Education 2019;10(2):26-30 